\title{
HUBUNGAN DIABETES MELITUS DENGAN KEJADIAN STROKE ISKEMIK DI RSUD DR. MOEWARDI SURAKARTA TAHUN 2010
}

\author{
Aulya Farra Ramadany, Listyo Asist Pujarini, Anika Candrasari \\ Fakultas Kedokteran, Universitas Muhammadiyah Surakarta \\ Correspondence to: Anika Candrasari \\ Email: Anika.Candrasari@ums.ac.id
}

\begin{abstract}
From survey at Dr. Moewardi Hospital in the year 2010, the incidence of stroke patients increase 5-7\% every year. Diabetes mellitus has a relationship with ischemic stroke through aterosklerosis. However, the relationship of diabetes mellitus as a risk of ischemic stroke remains uncertain due to diabetes is not a single factor for stroke. Research aim was to determine the relationship between the incidence of diabetes mellitus and ischemic stroke. It was conducted at the neurologi unit in Dr.Moewardi Hospital Surakarta, the design was a cross sectional with sample size of 132 people. The sampling technique used simple random sampling. The result is the number of ischemic stroke patients with diabetes mellitus by 47 people (71.21\%). From chi square analysis $\left(x^{2}\right) x^{2}=13.516$ obtained and $p<0.000$ with $a$ value of $O R=3.8$ and $I K=1.841$ to 7.869. Its mean that there was a relationship between diabetes mellitus and incident ischemic stroke and people with diabetes mellitus have a risk 3,8 more times will got stroke ischemic than people without diabetes mellitus.
\end{abstract}

Keywords: diabetes mellitus, ischemic, stroke

\section{PENDAHULUAN}

Trend penyakit beberapa puluh tahun belakangan ini mengalami perubahan. Dulu didominasi oleh penyakit infeksi sekarang cenderung ke arah penyakit metabolik. Penyakit metabolik yang sering dijumpai saat

ini antara lain hipertensi, diabetes melitus, dan stroke. Sekarang stroke menempati urutan ketiga sebagai penyakit mematikan setelah penyakit jantung dan kanker, sedangkan di Indonesia stroke menempati urutan pertama sebagai penyebab kematian di rumah sakit (Aliah dkk, 2007). Dalam skala global, stroke sekarang berada dalam peringkat kedua, di bawah penyakit jantung iskemik sebagai penyebab kematian dan merupakan faktor utama penyebab kecacatan serius. Di Amerika, pada tahun 2002, jumlah orang meninggal karena stroke sekitar 162.672 orang. Jumlah tersebut setara dengan 1 di antara 15 kematian di Amerika Serikat. Saat ini ada 4 juta orang di Amerika Serikat yang hidup dalam keterbatasan fisik akibat stroke, dan 15-30\% di antaranya menderita cacat menetap (Centers for Disease Control and Prevention, 2009).

Berdasarkan laporan European Journal of Neurology pada 2005 mengungkapkan bahwa di beberapa negara Uni Eropa, seperti Islandia, Norwegia, dan Swiss, insidensi stroke diperkirakan 1,1 juta orang setiap tahunnya (Valery F, 2009). Di Asia yang kebanyakan merupakan negara berkembang jumlah penderita stroke lebih banyak daripada di negara maju. Konferensi Stroke Internasional yang diadakan di Wina, Austria, tahun 2008 juga mengungkapkan bahwa di kawasan Asia jumlah kasus stroke terus meningkat (Soemarmo, 2008).

Angka kejadian stroke di Indonesia meningkat dengan tajam. Saat ini Indonesia merupakan negara dengan jumlah penderita stroke terbesar di Asia. Data stroke yang dikeluarkan oleh Yayasan Stroke Indonesia menyatakan pada tahun 2004, penelitian di sejumlah rumah sakit menemukan pasien rawat inap karena stroke jumlahnya sekitar 23.000 orang. Berdasarkan 
Riset Kesehatan Dasar (Riskesdas) tahun 2007 mendata kasus stroke di wilayah perkotaan di 33 provinsi dan 440 kabupaten, hasilnya adalah penyakit stroke merupakan pembunuh utama di kalangan penduduk perkotaan, sebagai salah satu contoh di Surakarta sebagai kota yang sedang berkembang pesat dengan RSUD Dr. Moewardi yang merupakan rumah sakit negeri rujukan daerah Surakarta. Menurut kepala unit saraf rumah sakit (RS) Dr. Moewardi Surakarta Prof. DR. dr. H.Suroto, Sp.S (K) "Jumlah penderita stroke mengalami peningkatan dari tahun ke tahun hingga 5-7 persen". Apabila tidak ada upaya penanggulangan stroke yang lebih baik maka jumlah penderita stroke pada tahun 2020 diprediksikan akan meningkat 2 kali lipat (Wiwit S, 2010). Data survei di RSUD Dr. Moewardi pada tahun 2010 jumlah pasien stroke iskemik sebanyak 503, dengan jumlah pasien stroke iskemik 275, lebih banyak daripada stroke hemoragik.

Penyebab tingginya angka kejadian stroke di Indonesia lebih disebabkan karena gaya dan pola hidup masyarakat yang tidak sehat, seperti malas bergerak, makanan berlemak dan kolesterol tinggi, sehingga banyak diantara mereka mengidap penyakit yang menjadi pemicu timbulnya serangan stroke. Saat ini serangan stroke lebih banyak dipicu oleh adanya hipertensi yang disebut sebagai silent killer, diabetes melitus, obesitas dan berbagai gangguan kesehatan yang terkait dengan penyakit degeneratif (Waspadji, 2007).

Diabetes melitus (DM) adalah suatu sindroma gangguan metabolisme dengan hiperglikemia yang tidak semestinya sebagai akibat suatu defisiensi sekresi insulin atau berkurangnya efektifitas biologis dari insulin atau keduanya dan merupakan suatu penyakit degeneratif yang angka kejadiannya cukup tinggi, di berbagai negara juga merupakan salah satu penyakit yang menjadi masalah kesehatan masyarakat. World Health Organization (WHO) memperkirakan jumlah penderita diabetes melitus mencapai lebih dari 180 juta jiwa diseluruh dunia. Kejadian ini akan meningkat dua kali lipat di tahun 2030 dan Indonesia menempati urutan ke-4 di dunia (WHO, 2006).

Penyebab diabetes melitus menjadi stroke iskemik salah satunya adalah adanya suatu proses aterosklerosis. Kira-kira $30 \%$ pasien dengan aterosklerosis otak terbukti adalah penderita diabetes. Terjadinya hiperglikemia menyebabkan kerusakan dinding pembuluh darah besar maupun pembuluh darah perifer disamping itu juga akan meningkatkan agegrat platelet dimana kedua proses tersebut dapat menyebabkan aterosklerosis. Hiperglikemia juga dapat meningkatkan viskositas darah yang kemudian akan menyebabkan naiknya tekanan darah atau hipertensi dan berakibat terjadinya stroke iskemik. Proses makroangiopati dianggap sangat relevan dengan stroke dan juga terdapat bukti adanya keterlibatan proses makroangiopati yang ditandai terjadinya stroke lakunar pada penderita diabetes melitus(Gilroy, 2000; Hankey dan Lees, 2001; Ryden et al 2007).

Dalam penelitian Antonious \& Silliman pada tahun 2005 dalam jurnalnya Northeast Florida Medicine mengungkapkan bahwa diabetes melitus terbukti sebagai faktor risiko stroke dengan peningkatan risiko relatif pada stroke iskemik 1.6 sampai 8 kali. Hal ini didukung dengan penelitian dalam jurnal National Stroke Associationyang menyatakan orang dengan diabetes berisiko terkena stroke 4 kali dari pada seseorang yang tidak menderita diabetes. Namun menurut penelitian dalam Diabetes Care Journal (Richard J. Steven et al, 2004) menyatakan bahwa diabetes melitus bukan merupakan faktor tunggal terjadinya stroke, ada beberapa faktor lain yang berpengaruh untuk memicu terjadinya stroke sehingga hubungan antara diabetes melitus dan stroke masih sulit dibuktikan. Pernyataan tersebut juga didukung pernyataan dalam British Journal (Sander dirk et al, 2011) yang menyatakan bahwa hubungan diabetes dengan stroke masih belum jelas (Gofir, 2009).

Berdasarkan latar belakang yang telah diuraikan di atas, maka dirumuskan masalah penelitian seperti berikut: "Apakah terdapat hubungan antara diabetes melitus dengan kejadian stroke iskemik di RSUD Dr.Moewardi Surakarta?"

Tujuan penelitian ini adalah menjawab rumusan permasalahan diatas yaitu untuk mengetahui hubungan antara diabetes melitus dengan kejadian stroke iskemik di RSUD Dr.Moewardi Surakarta. Manfaat penelitian ini adalah secara teoritis diharapkan dapat menambah ilmu pengetahuan di bidang kedokteran dan juga diharapkan dapat digunakan sebagai dasar untuk penelitian selanjutnya. Secara praktis bagi klinisi/ dokter, apabila terbukti diabetes melitus sebagai faktor risiko stroke iskemik, maka penelitian ini dapat bermanfaat bagi para klinisi dalam 
mengambil tindakan preventif agar dapat diberikan lebih awal dan tepat pada penderita dengan faktor risiko,sehingga dapat menurunkan insidensi stroke iskemik. Sedangkan bagi masyarakat yang merupakan sasaran tindakan promotif dan preventif, dengan mengenal faktor risiko stroke diharapkan masyarakat umum lebih berupaya melakukan pencegahan stroke dengan lebih terarah. Untuk penderita stroke adalah dengan diketahuinya faktor risiko stroke, penderita bisa lebih melakukan tindakan preventif agar tidak menjadi rekurens.

\section{METODE PENELITIAN}

Penelitian ini termasuk analitik observasional dengan pendekatan cross sectional. Penelitian dilakukan di unit rawat inap bagian penyakit saraf RSUD Dr. Moewardi Surakarta pada bulan September - Oktober 2011 dengan pengambilan data rekam medis tanggal 1 Januari 2010- 31 Desember 2010.

Subyek penelitian ini adalah semua pasien stroke iskemik yang menjalani rawat inap di bagian saraf di RSUD Dr. Moewardi Surakarta, dengan kriteria inklusi (Usia 40-89 tahun, menderita stroke iskemik dan bukan stroke, yang telah diperiksa kadar glukosa darah, menderita stroke iskemik pertama kali atau rekuren) dan eksklusi
(Pasien stroke hemoragik, pasien dengan data rekam medis yang tidak lengkap). Pengambilan sampel di lakukan secara simple random sampling dengan besar sampel sebanyak 132 pasien.

Variable terikat dalam penelitian ini adalah stroke iskemik. Diagnosis stroke iskemik didasarkan menggunakan gold standart yaitu CT scan yaitu didapatkan gambaran hipodens (Gofir, 2009). Variable bebas adalah diabetes melitus. Penegakkan diagnosis diabetes melitus berdasarkan gejala klasik yaitu polidipsi, polifagi, dan poliuria dengan pemeriksaan glukosa darah sewaktu $\geq 200 \mathrm{mg} / \mathrm{dl}$, gula darah puasa $\geq 126 \mathrm{mg} /$ dl dan tes toleransi glukosa oral (TTGO) $\geq 200$ $\mathrm{mg} / \mathrm{dl}$ (Arisman, 2010). Variable luar usia, jenis kelamin, kebiasaan merokok, penyakit jantung, dan hiperlipidemia. Pada penelitian ini tehnik analisis data yang digunakan adalah chi square.

\section{HASIL DAN PEMBAHASAN}

Hasil dari survei peneliti di RSUD Dr. Moewardi pada tahun 2010 jumlah pasien stroke yang ditemukan sebesar 503 orang, dengan jumlah pasien stroke iskemik 275 orang, data yang memenuhi kriteria inklusi subyek penelitian sebanyak 132 sampel dengan menggunakan metode pengambilan sampel secara simple random sampling. Sehingga didapat hasil sebagai berikut:

Tabel 1. Distribusi data menurut jenis kelamin dan usia

\begin{tabular}{|c|c|c|c|c|c|c|c|c|c|c|}
\hline & & & \multicolumn{4}{|c|}{ Stroke iskemik } & \multicolumn{4}{|c|}{ Bukan stroke iskemik } \\
\hline & & & $\mathrm{N}$ & & $\%$ & & 1 & & & $\%$ \\
\hline \multicolumn{11}{|c|}{ Jenis kelamin } \\
\hline & Laki-laki & & 39 & & 59,09 & & & & & $\overline{9,3}$ \\
\hline & Perempuan & & 27 & & 40,91 & & & & &, 61 \\
\hline \multicolumn{11}{|c|}{ Usia } \\
\hline \multicolumn{3}{|c|}{$40-49$} & 8 & & \multicolumn{2}{|l|}{12} & \multicolumn{2}{|c|}{21} & \multicolumn{2}{|c|}{32} \\
\hline \multicolumn{3}{|c|}{$50-59$} & 18 & & \multicolumn{2}{|l|}{27} & \multicolumn{2}{|c|}{21} & \multicolumn{2}{|c|}{32} \\
\hline \multicolumn{3}{|c|}{$60-69$} & 26 & & \multicolumn{2}{|l|}{39} & \multicolumn{2}{|c|}{14} & \multicolumn{2}{|c|}{21} \\
\hline \multicolumn{3}{|c|}{$70-79$} & 13 & & \multicolumn{2}{|l|}{19} & \multicolumn{2}{|c|}{8} & \multicolumn{2}{|c|}{12} \\
\hline \multicolumn{3}{|c|}{$80-89$} & 1 & & \multicolumn{2}{|l|}{3} & 2 & & \multicolumn{2}{|c|}{3} \\
\hline \multicolumn{5}{|c|}{$\begin{array}{l}\text { Tabel 2. Distribusi data pada kejadian stroke iskemik } \\
\text { dan bukan stroke iskemik terhadap DM }\end{array}$} & Tabel 3. & \multirow{2}{*}{\multicolumn{5}{|c|}{$\begin{array}{l}\text { Distribusi data pada kejadian stroke } \\
\text { iskemik dan bukan stroke iskemik terhadap } \\
\text { hiperlipidemia }\end{array}$}} \\
\hline \multirow{3}{*}{ Diagnosis } & Stroke & Bukan stroke & X? & $\mathrm{D}$ & & & & & & \\
\hline & iskemik & iskemik & \multirow{2}{*}{\multicolumn{2}{|c|}{$\mathrm{N}$}} & \multirow{2}{*}{\multicolumn{2}{|c|}{ Diagnosis }} & \multicolumn{2}{|c|}{ Stroke iskemik } & \multicolumn{2}{|c|}{$\begin{array}{l}\text { Bukan stroke } \\
\text { iskemik }\end{array}$} \\
\hline & $\mathrm{N}$ & $\mathrm{N}$ & & & & & \multicolumn{2}{|l|}{$\mathrm{N}$} & \multirow{2}{*}{$\frac{N}{7}$} & $\%$ \\
\hline $\mathrm{DM}(+)$ & 47 & 26 & \multirow{2}{*}{13.516} & \multirow{2}{*}{0.000} & Hiperlip & lemia $(+)$ & 16 & 24,24 & & 10,61 \\
\hline DM (-) & 19 & 40 & & & Hiperlip & demia (-) & 50 & 75,76 & 59 & 89,39 \\
\hline & & & & & JUN & LAH & 66 & 100 & 66 & 100 \\
\hline
\end{tabular}


Tabel 4. Distribusi data pada kejadian stroke iskemik dan bukan stroke iskemik terhadap penyakit jantung

\begin{tabular}{ccccc} 
Diagnosis & Stroke iskemik & \multicolumn{2}{c}{$\begin{array}{c}\text { Bukan stroke } \\
\text { iskemik }\end{array}$} \\
& $\mathrm{N}$ & $\%$ & $\mathrm{~N}$ & $\%$ \\
Penyakit jantung (+) & 4 & 6,06 & 0 & 0 \\
Penyakit jantung (-) & 62 & 93,94 & 66 & 100 \\
JUMLAH & 66 & 100 & 66 & 100
\end{tabular}

Dari 132 sampel yang terdiagnosis stroke iskemik sebanyak 66 kasus sedangkan 66 penderita lainnya termasuk dalam bukan stroke iskemik yang merupakan gabungan dari penyakitpenyakit saraf yang lain seperti epilepsi, sefalgia, vertigo, iskhalgia, parkinson, meningitis dan hidrosefalus. Pada tabel 1 didapatkan sampel dengan jenis kelamin laki-laki lebih banyak daripada perempuan. Hal ini sesuai dengan hasil penelitian Satu Mustanoja, MDet al dalam jurnal American Heart Assosiation pada tahun 2010 dan ini didukung dengan hasil riset kesehatan dasar Indonesia tahun 2007 yang menyatakan kalau jenis kelamin laki-laki lebih berisiko terkena stroke dibanding perempuan. Hal ini dimungkinkan karena buruknya pola hidup seperti merokok, makan-makanan yang berisiko seperti makanan manis, makanan asin, berpenyedap, berlemak, dan mengandung banyak kolesterol yang di mana perilaku tersebut akan menganggu elastisitas pembuluh darah dan bisa juga menyebabkan penyumbatan yang akan menjadi aterosklerosis.

Namun hasil penelitian tersebut berbeda dengan penelitian dalam jurnal National Center for Health Statistic yang menyebutkan berdasarkan jenis kelamin pada individu yang terkena stroke iskemik pertama kali, ditemukan rata-rata kejadian stroke iskemik lebih banyak yang jenis kelamin perempuan dibandingkan laki-laki (Gofir, 2009). Hal ini mungkin berhubungan dengan kondisi khusus yang disebut Risk Factors Unique yaitu ada beberapa faktor risiko stroke iskemik yang khusus didapatkan pada wanita, seperti kehamilan dimana kondisi tersebut dinamakan diabetes gestasional yaitu suatu kondisi yang disebabkan intoleransi glukosa yang ditemukan pertama kali saat hamil dan dimana kondisi diabetes melitus tersebut bisa menetap setelah melahirkan.

Pada tabel 1 juga didapatkan sampel terbanyak pada usia 60-69 tahun. Menurut hasil riset kesehatan dasar Indonesia tahun 2007 bahwa usia di atas 65 tahun berisiko tinggi terkena stroke daripada di bawah 65 tahun. Setelah usia 50 tahun tampak kecenderungan bahwa arteriarteri serebral yang kecil juga terkena proses arterosklerosis. Penyempitan yang disebabkan oleh plak arterosklerosis bisa mencakup 8090\% lumen arteri (Valery, 2009). Namun, saat usia di atas 75 tahun insidennya mengalami penurunan. Seperti pada jurnal National Institutes of Neurological Disorders and Stroke tahun 2008 rasio insiden pria terhadap wanita pada usia 55-64 tahun adalah 1,25, pada usia 65-74 tahun adalah 1,50 pada usia 75-84 tahun adalah 1,07, dan pada usia $\geq 85$ tahun adalah 0,76 (Carnethon et al, 2009). Hal ini menurun karena usia rata-rata orang di Amerika yaitu 72,3 tahun pada pria dan wanita 79,1 tahun sehingga jumlah insiden pria lebih sedikit (Maryam dkk, 2008) sedangkan usia rata-rata orang Indonesia menurut BAPPENNAS yaitu 70 tahun.

Pada tabel 2, distribusi kejadian stroke iskemik dan kejadian bukan stroke iskemik terhadap DM dan non DM, didapatkan hasil $71,21 \%$ penderita stroke iskemik dengan DM. Hal ini menunjukkan bahwa kondisi DM berpengaruh positif dan merupakan faktor risiko stroke iskemik (Feigin, 2009). Prevalensi penderita stroke dengan hipertensi (tekanan darah sistolik $\geq 140 \mathrm{mmHg}$ dan atau tekanan darah diastolik $\geq 90 \mathrm{mmHg}$ ) cukup tinggi, mencapai $67,5 \%$. Hal tersebut terjadi karena diabetes akan meningkatkan risiko untuk terjadinya hipertensi. Diabetes adalah kondisi dimana terjadi peningkatan insulin dalam darah pada DM tipe II yang dewasa ini semakin meningkat jumlahnya di masyarakat, kondisi tersebut meningkatkan penyerapan jumlah natrium didalam tubuh. Penyerapan natrium akan meningkatkan kadar kalium dalam darah dan akan menyebabkan terstimulasikan sistem saraf simpatik. Hal ini diduga menyebabkan perubahan struktur dalam darah yang mempengaruhi fungsi jantung dan tekanan darah. Masalah vaskular yang timbul dikarenakan diabetes dan diperparah dengan hipertensi, pola makan yang tidak baik serta kurangnya aktivitas fisik. Sehingga diabetes adalah kondisi dimana secara tidak langsung akan mempengaruhi untuk terjadinya hipertensi. Pada penelitian ini kondisi pasien hipertensi dilakukan matching dengan kontrol.

Pada tabel 2, 3 dan 4, distribusi data pada kejadian stroke iskemik dan bukan stroke iskemik dengan DM dan non DM 
terhadap hiperkolestrolemia dan penyakit jantung, didapatkan hasil orang dengan stroke iskemik lebih banyak terkena penyakit jantung yaitu 4 orang dengan presentase $6,06 \%$ dan hiperlipidemia yaitu 14 orang dengan presentase $21,21 \%$ daripada orang yang tidak terkena stroke. Hal ini menunjukkan bahwa lipid yang tinggi berpengaruh positif dan merupakan faktor risiko independen terhadap risiko stroke iskemik (Tanne et al, 2001). Menurut Kamso et al (2002) pada penelitiannya tentang dislipidemia didapatkan lebih dari 50\% sampel yang ditemukan memiliki kolesterol yang tinggi dimana kolesterol yang tinggi merupakan faktor risiko yang penting untuk terjadinya aterosklerosis.

Kondisi DM sendiri, akan menyebabkan kerusakan dinding arteri sehingga membentuk bekuan darah yang disebut thrombus. Pada proses ini akan terjadi penurunan aliran darah lebih lanjut. Pada beberapa kasus thrombus akan membesar dan menutup lumen arteri, atau thrombus dapat terlepas dan membentuk emboli yang akan mengikuti aliran darah dan menyumbat arteri di daerah yang lain. Jaringan yang memperoleh vaskularisasi dari arteri yang tersumbat oleh emboli tersebut akan mati karena kehilangan suplai oksigen secara cepat, yang bila terjadi di jantung akan menyebabkan kerusakan pada jantung sehingga menjadi penyakit jantung (Gofir, 2009).

Pada kelompok bukan stroke iskemik terdapat 26 sampel yang menderita DM namun tidak terkena stroke iskemik. Padahal, kondisi dimana jika memiliki DM ditambah dengan faktor usia yang sudah tua seharusnya terkena stroke tetapi pada kenyataannya tidak terserang stroke. Hal ini dimungkinkan gaya hidup yang baik dan sehat cukup menolong dari ancaman terkena stroke. Gaya hidup yang baik dan sehat seperti tidak merokok, makan buah-buahan, mengurangi makanan yang berlemak dan berpenyedap serta melakukan aktivitas fisik yang rutin seperti minimal melakukan jalan kaki beberapa jam setiap hari (Arisman, 2010).

Nilai Odds Ratio (OR) yaitu 3,8 dan didapatkan Interval Kepercayaan (IK) $95 \%$ antara $1,841-7,869$ menunjukan adanya hubungan yang signifikan antara diabetes melitus dengan kejadian stroke iskemik. Hasil OR yang menunjukkan lebih dari 1 berarti diabetes melitus merupakan faktor risiko stroke iskemik dan orang yang terdiagnosis diabetes melitus memiliki peluang sebesar 3,8 kali lebih berisiko terkena stroke iskemik daripada orang tanpa diabetes melitus. Hal ini sesuai dengan penelitian-penelitian sebelumnya seperti dalam penelitian Antonious \& Silliman pada tahun 2005 dalam jurnalnya Northeast Florida Medicine mengungkapkan bahwa diabetes melitus terbukti sebagai faktor risiko stroke dengan peningkatan OR pada stroke iskemik 1.6 sampai 8 kali.

Interpretasi hasil regresi logistik didapatkan variabel yang berpengaruh terhadap stroke iskemik adalah diabetes melitus, jenis kelamin, dan hiperlipidemia. Karena hasil analisis bivariant mempunyai nilai $\mathrm{p}<0,25$. Namun pada usia dan penyakit jantung yang di analisis juga menggunakan regresi logistik hasilnya nilai $\mathrm{p}$ tidak memenuhi syarat sehingga gugur untuk bisa dilakukan ke tahap uji analisis multivariant. Kekuatan hubungan dapat dilihat dari nilai OR $(\operatorname{EXP}\{B\})$. Kekuatan hubungan dari yang terbesar ke yang terkecil adalah diabetes melitus $(\mathrm{OR}=3,315)$, hiperlipidemia $(\mathrm{OR}=2,345)$, dan jenis kelamin $(\mathrm{OR}=0,536)$. Hal tersebut sesuai dengan yang dinyatakan oleh Gofir (2009) yaitu urutan faktor-faktor risiko untuk terjadinya stroke iskemik dimulai dari yang tertinggi yaitu hipertensi, diabetes melitus, penyakit jantung, merokok, pemakaian alkohol, obesitas dan yang terakhir jenis kelamin dalam bukunya yang berjudul manajemen stroke.

Berdasarkan hasil perhitungan di atas dapat disimpulkan bahwa secara statistik terdapat hubungan antara diabetes melitus dengan kejadian stroke iskemik dimana kadar glukosa darah yang berlebih akan menganggu elastisitas pembuluh darah dan proses arterosklerosis mendominasi untuk terjadinya suatu emboli yang akan menyumbat dan menjadi stroke iskemik bila terkenanya di otak.

Kelemahan penelitian ini antara lain dikarenakan penelitian dilakukan tanpa follow up sehingga sulit untuk menetapkan mekanisme sebab akibat karena pengukuran terhadap faktor risiko dan efek dilakukan sekaligus pada saat yang sama, data diambil berdasarkan rekam medis yang kurang akurat di luar kendali penulis, jumlah sample yang diambil tidak selektif dan waktu serta tempat penelitian yang terbatas dan tidak diperhatikannya riwayat penderita dengan kadar glukosa yang tinggi yang pernah menderita stroke iskemik. 


\section{SIMPULAN}

Berdasarkan hasil penelitian yang telah dilakukan, maka dapat disimpulkan bahwa terdapat hubungan antara diabetes mellitus dengan kejadian stroke iskemik.

\section{SARAN}

Perlu diadakan penelitian lebih lanjut dengan memasukkan variabel-variabel luar seperti merokok,dan kemudian dilakukan analisa uji SPSS untuk melihat pengaruh dari masingmasing variabel. Kepada penderita diabetes mellitus diberikan edukasi yang baik dan benar untuk mengubah gaya hidup agar tidak berlanjut menjadi stroke iskemik.

\section{DAFTAR PUSTAKA}

Aliah, A., Kuswara, F.F., Limoo, R.A., dan Wuysang, G., 2007. Kapita Selekta Neurologi Edisi Kedua : Gambaran Umum. Yogyakarta: Gadjah Mada University Press.
Arisman., 2010. Obesitas, Diabetes melitus, dan Dislipidemia. Jakarta: EGC.

Gilroy, J., 2000.Basic Neurology 3rd ed. New York : McGraw-Hill.

Gofir, Abdul., 2009. Manajemen STROKE. Yogyakarta: Pustaka cendekia press.

Indiyarti, Riani., 2009. Perbandingan Kadar Gula Darah Sewaktu Pada Kedua Jenis Stroke. Surabaya : Trisakti University Press.

Waspadji, S., 2007. Komplikasi Kronik Diabetes : Mekanisme Terjadinay Diagnosis dan Strategi Pengelolaan. Dalam :Sudoyo, Aru. Buku Ajar Ilmu Penyakit Dalam. Ed 4. Jilid 3. Jakarta : FKUI.

WHO., 2006.Prevention of Diabetes Melitus,

Technical Report Series. 